Tropical Journal of Pharmaceutical Research January 2020; 19 (1): 189-194

ISSN: $1596-5996$ (print); 1596-9827 (electronic)

(C) Pharmacotherapy Group, Faculty of Pharmacy, University of Benin, Benin City, 300001 Nigeria.

\title{
Efficacy and safety of VEGFR inhibitors versus standard chemotherapy in Chinese patients with metastatic liver cancer: Results of a preliminary clinical trial
}

\author{
Dong Qian, Shuai Wang, Hongzhi Zhao*, Chen Zhang \\ Department of the Third Surgery, TianJin Nankai Hospital, Tianjin 300100, China
}

*For correspondence: Email: OmarWoodsgt|@yahoo.com; Tel: +86 2227022268

Sent for review: 30 May 2019

Revised accepted: 29 December 2019

\begin{abstract}
Purpose: To evaluate efficacy and safety of vandetanib with and without standard chemotherapy in Chinese patients with metastatic liver cancer.

Methods: Patients with confirmed diagnosis of metastatic liver cancer were randomized to receive vandetanib (300 mg per day in 28 days cycle) intravenously or standard chemotherapy (FOLFOX4) plus best supportive care. Efficacy measures such as overall survival (OS), objective response rate (ORR), and progression-free survival (PFS) were assessed after study drug treatment. Safety of vandetanib and FOLFOX4 was also assessed. Survival time with respect to disease progression was also assessed.

Results: Vandetanib + standard chemotherapy-based regimens showed significantly higher OS benefit when compared to vandetanib and chemotherapy alone. Objective response rate (ORR) was also favorable among the patients treated with combination therapy when compared with monotherapy. A similar trend was noted for PFS; treatment with vandetanib + chemotherapy showed significantly longer PFS when compared to vandetanib and chemotherapy alone, respectively. Trial results demonstrated that vandetanib as a monotherapy or in combination with standard chemotherapy appears to be safe.

Conclusion: The results of this trial may aid clinicians to select appropriate therapeutic intervention for patients with metastatic liver cancer.
\end{abstract}

Keywords: Vandetanib, Metastatic liver cancer, Chemotherapy, FOLFOX4, VEGFR inhibitors

\begin{abstract}
This is an Open Access article that uses a fund-ing model which does not charge readers or their institutions for access and distributed under the terms of the Creative Commons Attribution License (http://creativecommons.org/licenses/by/4.0) and the Budapest Open Access Initiative (http://www.budapestopenaccessinitiative.org/read), which permit unrestricted use, distribution, and reproduction in any medium, provided the original work is properly credited.

Tropical Journal of Pharmaceutical Research is indexed by Science Citation Index (SciSearch), Scopus, International Pharmaceutical Abstract, Chemical Abstracts, Embase, Index Copernicus, EBSCO, African Index Medicus, JournalSeek, Journal Citation Reports/Science Edition, Directory of Open Access Journals (DOAJ), African Journal Online, Bioline International, Open-J-Gate and Pharmacy Abstracts
\end{abstract}

\section{INTRODUCTION}

Liver cancer is one of the common types of malignancy worldwide, highly prevalent among men when compared to women. It is the most common reason of cancer-related mortality globally [1]. More than 78,000 of patients who were diagnosed with liver cancer belong to Asian countries, predominantly East Asian region [2].
Liver cancer is an important public health issue across the world dueto its poor prognosis and high death rate, thus new treatment modalities are urgently required for patients with Liver cancer [2]. Presently, anti-neoangiogenesis is one of the most novel approaches for the management of cancerous tumors. The process of neoangiogenesis was related with numerous vessel-related factors, and quickly growing tumor 
cells releases various growth factors under absence of oxygen condition, which stimulates tumor angiogenesis [3-5]. The VEGF/VEGF receptor signaling pathway is considered as one of the most important therapeutic targets [5-9]. Inhibition of this pathway has revealed strong clinical antitumor activity against different types of cancer [10].

Cytotoxic chemotherapeutic agents have not been mostly used in the management of advnaced stage of metastatic liver cancer. A first phase 3 trial investigated a systemic chemotherapy regimen with the FOLFOX4 containing three chemotherapeutic regimen namely as oxaliplatin, 5-fluorouracil [5-FU] and folinic acid [FA]), and have shown favorable survival outcome in Asian patients with metastatic liver cancer [11]. The use of FOLFOX [12] has become the standard systemic chemotherapy for metastatic liver cancer in China and the use of oxaliplatin has been approved by the China Food and Drug Administration. Even with the emergence of novel agents in the treatment of metastatic liver cancer, the prognosis of metastatic liver cancer remains poor with median survival of less than 1 year [13-17]. Thus, there is a clear need for a more effective and tolerable therapy for patients with metastatic liver cancer. Based on the above facts, it was assumed that the use of antiangiogenic therapy in combination with oxaliplatin containing systemic chemotherapy could provide more benefit in patients with metastatic liver cancer than cytotoxic chemotherapeutic agents as monotherapy such as oxaliplatin based therapy alone.

In the current clinical trial, it has been hypothesized that vandetanib, a mixed inhibitor of VEGFR and EGFR, in combination chemotherapeutic agents show a significant survival benefit as compared to chemotherapeutic agents as monotherapy among Chinese patients with metastatic liver cancer. The purpose of the current clinical trial was to evaluate efficacy and safety of Vandetanib with and without standard chemotherapy in Chinese patients with metastatic liver cancer.

\section{METHODS}

\section{Participants and treatment modalities}

The patients with confirmed diagnosis of metastatic liver cancer who had BCLC-C and stage $B$ of liver cancer with an ECOG PS range from $0-1$, and who had metastases were recruited. Exclusion criteria were hepatic loco- regional therapy within 28 days, current or past history of hepatic encephalopathy or current clinically meaningful ascites, active or uncontrolled clinically serious infection, and esophageal or gastric varices that required immediate intervention. Trial protocol and other essential documents were approved by the Institutional Review Board of Tianjin Nankai Hospital vide approval number: IRB/TJNH/07TJN/267-2018. In this clinical trial, the eligible participants were randomized to receive vandetanib (300 mg per day in 28 days cycle) intravenously or standard chemotherapy (FOLFOX4) plus best supportive care.

\section{Efficacy assessment}

Primary efficacy measures such as OS, ORR, and PFS were assessed after study drug treatment. Safety of vandetanib and FOLFOX4 was also assessed. Survival time with respect to disease progression was also assessed. Secondary objectives included pharmacokinetics assessment of vandetanib; assessment of immunogenicity after vandetanib treatment. Using RECIST Criteria, OS and PFS was recorded from each patient using CT scan and/or MRI. Moreover, the patients with $\mathrm{PR}$ or $\mathrm{CR}$ or stable disease or PD were recorded and summarized. Survival time of patients was derived from date of diagnosis of lung cancer to death due to of lung cancer or date of lost to follow up.

\section{Safety assessment}

Treatment-related adverse event (TEAE) or SAE observed in each patient was recorded. No reescalation was done for the patients who needed dose reductions. In addition, all patients who received repeated cycles of treatment were monitored for evidence of cumulative toxicity. Serious adverse events were followed until recovery, death or lost follow-up. Safety was measured through common terminology criteria for adverse events for adverse events (v 4.03).

\section{Statistical analysis}

Since the present investigation was designed as a preliminary investigation, therefore formal calculation of sample size was not carried out. Safety and efficacy analyses are for those who received any quantity of vandetanib, regardless of their eligibility. In the present trial, PFS and OS and response rate were analyzed between both treatment groups using a log-rank test. SigmaPlot was used for analysis of data (version 11.0) 


\section{RESULTS}

\section{Patient disposition}

Out of 180 patients, a total of 126 patients were enrolled and randomly allocated to Vandetanib ( $\mathrm{n}$ = 42) or Vandetanib plus chemotherapy $(n=42)$ or Vandetanib + chemotherapy $(n=42)$ from Jan 2017 to Dec 2018. Of these, all enrolled pts were subjected in the analysis.

\section{Demographic and baseline characteristics}

Both treatment groups have similar demography and baseline characteristics. The patient demography and clinical features of all recruited patients are shown in Table 1.

\section{Efficacy}

Treatment with vandetanib + chemotherapy showed significantly higher OS benefit when compared to Vandetanib and Chemotherapy alone, respectively (OS: median $14.55 \mathrm{~m}$ versus $9.59 \mathrm{~m}$ versus $10.71 \mathrm{~m})$. Similar trend was noted for PFS, treatment with Vandetanib + Chemotherapy showed significantly longer PFS when compared to Vandetanib and Chemotherapy alone, (PFS: median $11.15 \mathrm{~m}$ versus $5.34 \mathrm{~m}$ versus $6.82 \mathrm{~m})$. Overall Survival and PFS for patients after treatment with Vandetanib and/or chemotherapy is described in Figure 1 and Figure 2, respectively. The best overall response including disease control rate and overall response rate was favorable for the patients who were treated with combination when compared to monotherapy treatment.

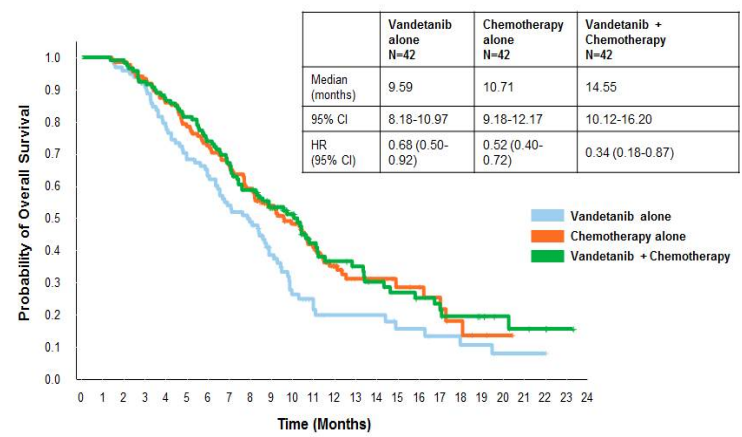

Figure 1: Overall survival (OS) for patients after treatment with vandetanib and/or chemotherapy

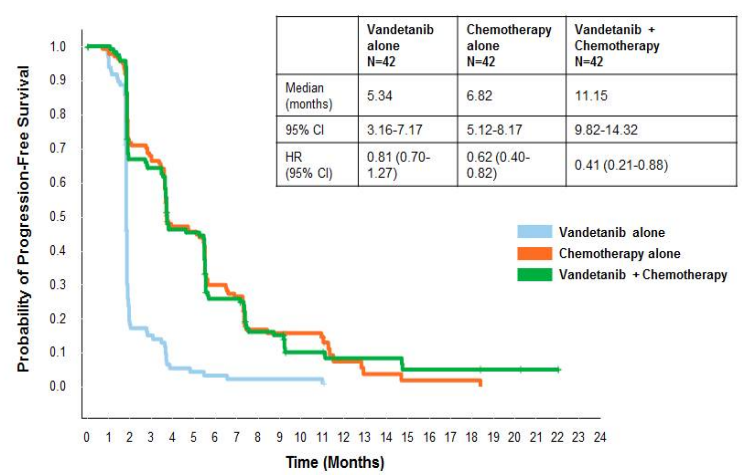

Figure 2: Progression-free survival (PFS) for patients after treatment with Vandetanib and/or chemotherapy

Table 1: Patients' characteristics

\begin{tabular}{|c|c|c|c|}
\hline Variable & Vandetanib lone $(\mathrm{N}=42)$ & $\begin{array}{l}\text { Chemotherapy alone } \\
\qquad(\mathrm{N}=42)\end{array}$ & $\begin{array}{c}\text { Vandetanib+ } \\
\text { chemotherapy } \\
(\mathrm{N}=42)\end{array}$ \\
\hline Age, (years), mean (SD) & $58.6(9.16)$ & $57.2(8.7)$ & $55.2(68.7)$ \\
\hline Nex, 10 Male & 70 & 60 & 80 \\
\hline Female & 30 & 40 & 20 \\
\hline Initial pathological diagnosis & & & \\
\hline Histopathological & 40 & 50 & 61 \\
\hline Cytological & 30 & 35 & 19 \\
\hline $\begin{array}{l}\text { Biochemical Assay and } \\
\text { Imaging }\end{array}$ & 10 & 15 & 20 \\
\hline ECOG performance status & & & \\
\hline $\begin{array}{l}0 \\
1\end{array}$ & $\begin{array}{l}55.0 \\
45.0\end{array}$ & $\begin{array}{l}70 \\
30\end{array}$ & $\begin{array}{l}60 \\
40\end{array}$ \\
\hline $\begin{array}{l}\text { Duration of disease, median, } \\
\text { months } \\
B C L C \text { classification }\end{array}$ & 8.5 & 7.9 & 8.2 \\
\hline Stage B & 29 & 46 & 52 \\
\hline Stage C & 71 & 54 & 48 \\
\hline Viral hepatitis B test positive & 100.0 & 100.0 & 100.0 \\
\hline
\end{tabular}

Abbreviations: BCLC = Barcelona Clinic Liver Cancer = ECOG, Eastern Cooperative Oncology Group; n, number of patients; $\mathrm{N}$ = total population size; $\mathrm{SD}$ = standard deviation 
The disease control rate and overall response rate were 60 and $68 \%$, respectively. The best ORR after treatment with vandetanib and/or chemotherapy is summarized in Table 2 .

\section{Safety and tolerability}

Majority of patients in combination group experienced at least 1 treatment emergent adverse event (TEAE) regardless of relationship to trial drug; and at least 1 TEAE considered as trial drug related by the investigator. The trial drug related treatment emergent adverse events after trial treatment are summarized in Table 3. The most common TEAEs were decreased neutrophil count, decreased white blood cell count, diarrhea, increased aspartate aminotransferase, and hyponatremia.

\section{DISCUSSION}

The current investigation is the first trial carried out to compare the efficacy and safety of Vandetanib with and without standard chemotherapy in Chinese patients with metastatic liver cancer. No direct comparison of Vandetanib and standard chemotherapy as monotherapy or combination therapy was performed. Moreover, there has been no comparison of effectiveness and safety profiles of Vandetanib and standard chemotherapy in Chinese metastatic liver cancer patients till date. Thus, the present trial was designed to evaluate whether vandetanib, a mixed inhibitor of VEGFR and EGFR in combination chemotherapeutic agents show a significant survival benefit versus chemotherapeutic agents as monotherapy in Chinese patients with metastatic liver cancer.

Table 2: Tumour Response after treatment with Vandetanib and/or chemotherapy

\begin{tabular}{|c|c|c|c|}
\hline $\begin{array}{l}\text { Tumor } \\
\text { response }\end{array}$ & $\begin{array}{l}\text { Vandetanib } \\
\text { alone }(n=42)\end{array}$ & $\begin{array}{l}\text { Chemotherapy } \\
\text { alone }(n=42)\end{array}$ & $\begin{array}{c}\text { Vandetanib+ } \\
\text { chemotherapy } \\
(n=42)\end{array}$ \\
\hline \multicolumn{4}{|l|}{ Disease } \\
\hline $\begin{array}{l}\text { control rate } \\
(\mathrm{CR}+\mathrm{PR}+\mathrm{SD}), \\
\% \\
\text { Overall }\end{array}$ & 21 & 23 & 60 \\
\hline $\begin{array}{l}\text { response rate } \\
\text { (CR+PR) } \\
\text { Best overall tum } \\
\text { Complete }\end{array}$ & 16 & 23 & 68 \\
\hline $\begin{array}{l}\text { response } \\
\text { (CR) }\end{array}$ & 11 & 14 & 32 \\
\hline $\begin{array}{l}\text { Partial } \\
\text { response } \\
\text { (PR) }\end{array}$ & 24 & 28 & 69 \\
\hline $\begin{array}{l}\text { Stable } \\
\text { disease (SD) }\end{array}$ & 65 & 75 & 34 \\
\hline $\begin{array}{l}\text { Progressive } \\
\text { disease (PD) }\end{array}$ & 29 & 32 & 11 \\
\hline
\end{tabular}

Table 2: Trial drug related treatment emergent adverse events after trial treatment

\begin{tabular}{lccc}
\hline Preferred term & $\begin{array}{c}\text { Vandetanib } \\
\text { alone }(\mathbf{n = 4 2 )}\end{array}$ & $\begin{array}{c}\text { Chemotherapy } \\
\text { alone }(\mathbf{n = 4 2 )}\end{array}$ & $\begin{array}{c}\text { Vandetanib + } \\
\text { chemotherapy } \\
(\mathbf{n}=\mathbf{4 2}) \\
\mathbf{N}\end{array}$ \\
\hline Patients with $\geq 1$ trial drug related TEAE & 38 & 41 & 42 \\
Neutrophil count decreased & 2 & 2 & 2 \\
White blood cell count decreased & 1 & 1 & 2 \\
Neutropenia & 3 & 1 & 3 \\
Diarrhea & 3 & 1 & 2 \\
Fatigue & 2 & 1 & 3 \\
Hepatic hemorrhage & 1 & 2 & 2 \\
Wound complication & 1 & 1 & 4 \\
Aspartate aminotransferase increased & 1 & 2 & 2 \\
Blood bilirubin increased & 2 & 1 & 2 \\
Gamma-glutamyl transferase increased & 1 & 1 & 4 \\
Febrile neutropenia & 2 & 2 & 2 \\
\hline
\end{tabular}

Note: $\mathrm{n}$, number of patients; $\mathrm{N}$ : Total sample size; TEAE, treatment emergent adverse events 
Vandetanib + Chemotherapy combination regimens showed significantly greater OS and PFS than the monotherapy treatment. The objective response was also favorable among the patients treated with combination regimens, when compared with monotherapy. The present trial results showed that combination regimens were superior to monotherapy in improving OS, PFS and ORR, and it offered significantly greater clinical benefits for advanced stage liver cancer patients than monotherapy. The results of the present trial may help clinicians to select appropriate treatment modalities for advanced stage liver cancer patients. These results are consistent with previous reports [14-17]. In general, Vandetanib and Chemotherapy as combination or monotherapy were well-tolerated in the advanced stage liver cancer patients. Earlier, ramucirumab in combination with Chemotherapy (FOLFOX regimen) has been tested in patients with advanced esophageal, gastroesophageal junction, or gastric adenocarcinoma [19-20] or metastatic colorectal cancer [19]. To the best of our knowledge, this is the first trial to test this combination of Vandetanib with FOLFOX regimen in patients with metastatic liver cancer. In the present trial, the best overall response including disease control rate and ORR was favorable for the patients who were treated with combination as compared to monotherapy treatment.

In REACH study, the most common severe TEAE of ramucirumab in Asians patients with metastatic liver cancer were hypertension. Safety of ramucirumab therapy for Asians was similar to non-Asians [22]. In the present clinical trial, the most common grade $\geq 3$ TEAEs (occurring in $\geq 5$ $\%$ of patients) after administration of Vandetanib with FOLFOX regimen were hypertension followed by increased aspartate aminotransferase concentration and thrombocytopenia. This is in consistent with REACH trial [22], with similar safety profile. Nonetheless, most of these TEAEs are common in patients with HCC due to underlying malignancies and liver diseases. Despite of some differences in clinical trial design such as different setting and line of treatment between present clinical trial and REACH trial, the toxicities of ramucirumabFOLFOX4 are more likely to be associated with chemotherapy.

\section{Limitations of the study}

The present trial was conducted at single hospital in China; therefore, results may not be generalized to other population. Due to low sample size of present study, large clinical trial with appropriate sample size warranted to designed the efficacy and safety of Vandetanib + Chemotherapy (FOLFOX regimen) in Chinese patients with liver metastasis to further confirm the finding of this trial.

\section{CONCLUSION}

The present trial results show the superior efficacy of the combination of vandetanib + chemotherapy (FOLFOX regimen) compared to monotherapy in Chinese patients with metastatic liver cancer. The results of the present trial may help clinicians to select appropriate the therapeutic intervention for patients with metastatic liver cancer. However, a larger clinical trial is needed to confirm the generalibility of present finding before clinical use.

\section{DECLARATIONS}

\section{Conflict of interest}

No conflict of interest is associated with this work.

\section{Contribution of authors}

We declare that this work was done by the authors named in this article and all liabilities pertaining to claims relating to the content of this article will be borne by the authors. Dong Qian and Shuai Wang contribute to this work equally. This paper was written by both Dong Qian and Shuai Wang. The whole study was funded by Hongzhi Zhao. Chen Zhang gave suggestions in designing this study.

\section{Open Access}

This is an Open Access article that uses a funding model which does not charge readers or their institutions for access and distributed under the terms of the Creative Commons Attribution License (http://creativecommons.org/licenses/by/ 4.0) and the Budapest Open Access Initiative (http://www.budapestopenaccessinitiative.org/rea d), which permit unrestricted use, distribution, and reproduction in any medium, provided the original work is properly credited.

\section{REFERENCES}

1. Yang JD, Roberts LR. Epidemiology and Management of Hepatocellular Carcinoma. Infect Dis Clin North Am 2010; 24(4): 899-919.

2. Cheng AL, Guan Z, Chen Z, Tsao CJ, Qin S, Kim JS, Yang TS. Efficacy and safety of sorafenib in patients with advanced hepatocellular carcinoma according to 
baseline status: subset analyses of the phase III Sorafenib Asia-Pacific trial. Eur J Cancer 2012; 48(10):1452-1465.

3. Ana FB, Ana MA, José GT, Maria FB. Targeting Hepatocellular Carcinoma: What did we Discover so Far? Oncol Rev 2016; 10(2): 302.

4. Sun W, Cabrera R. Systemic Treatment of Patients with Advanced, Unresectable Hepatocellular Carcinoma: Emergence of Therapies. J Gastrointest Cancer2018; 49(2):107-115.

5. Llovet JM, Ricci S, Mazzaferro V, Hilgard P, Gane E, Blanc JF, de Oliveira AC. Sorafenib in advanced hepatocellular carcinoma. N Engl J Med 2008; 359(4):378-390.

6. Cheng AL, Kang YK, Chen Z, Tsao CJ, Qin S, Kim JS, Luo R. Efficacy and safety of sorafenib in patients in the Asia-Pacific region with advanced hepatocellular carcinoma: a phase III randomised, double-blind, placebo-controlled trial. Lancet Oncol 2009; 10(1):25-34.

7. Kudo M, Finn RS, Qin S, Han KH, Ikeda K, Piscaglia F, Baron A. Lenvatinib versus sorafenib in first-line treatment of patients with unresectable hepatocellular carcinoma: a randomised phase 3 non-inferiority trial. Lancet 2018; 391(10126):1163-1173.

8. Bruix J, Qin S, Merle P, Granito A, Huang YH, Bodoky G, Pracht M. Regorafenib for patients with hepatocellular carcinoma who progressed on sorafenib treatment (RESORCE): a randomised, double-blind, placebocontrolled, phase 3 trial. Lancet 2017; 389(10064):5666.

9. Ghassan K, Abou-A Cabozantinib in Patients with Advanced and Progressing Hepatocellular Carcinoma. N Engl J Med 2018; 379:54-63

10. Ferrara N, Gerber HP, LeCouter J. The biology of VEGF and its receptors. Nat Med 2003; 9(6):669-76.

11. Zhu AX, Duda DG, Sahani DV, Jain RK. HCC and angiogenesis: possible targets and future directions. Nat Rev Clin Oncol 2011;8(5):292-301.

12. Lu D, Shen J, Vil MD, Zhang $H$, Jimenez $X$, Bohlen $P$. Tailoring in vitro selection for a picomolar affinity human antibody directed against vascular endothelial growth factor receptor 2 for enhanced neutralizing activity. $J$ Biol Chem 2003 31; 278(44):43496-43507.

13. Zhu Z, Hattori K, Zhang H, Jimenez X, Ludwig DL, Dias $S$. Inhibition of human leukemia in an animal model with human antibodies directed against vascular endothelial growth factor receptor 2. Correlation between antibody affinity and biological activity. Leukemia2003; 17(3):604611.

14. Zhu AX, Park JO, Ryoo BY, Yen CJ, Poon R, Pastorelli $D$. Ramucirumab versus placebo as second-line treatment in patients with advanced hepatocellular carcinoma following first-line therapy with sorafenib (REACH): a randomised, double-blind, multicentre, phase 3 trial. Lancet Oncol 2015; 16(7):859-870.

15. Andrew X. Zhu et al. REACH-2: A randomized, doubleblind, placebo-controlled phase 3 trial of ramucirumab versus placebo as second-line treatment in patients with advanced hepatocellular carcinoma (HCC) and elevated baseline alpha-fetoprotein (AFP) following first-line sorafenib. Gastrointestinal (non-colorectal) cancer. DOI: 10.1200/JCO.2018.36.15_suppl.4003 Journal of Clinical Oncology 36, no. 15_suppl (May 20 2018) 4003-4003.

16. Qin S, Bai Y, Ye S, Fan J, Lim HL, Cho Y, Thongprasert $S$, Chao $Y$, Rau K, Sun $Y$ et al. phase III trial of oxaliplatin plus 5-fluorouracil/leucovorin (FOLFOX4) versus doxorubicin as palliative systemic chemotherapy in advanced HCC in Asian patients. J Clin Oncol2010; 28(15s):4008.

17. Qin SK, Kruger E, Tan SC, Cheng SQ, Yao XX, Liang J. Cost-effectiveness analysis of oxaliplatin plus fluorouracil/leucovorin (FOLFOX4) compared to sorafenib for treatment of advanced hepatocellular carcinoma patients in China. ISPOR 7th Asia-Pacific Conference. Available from: https://www.ispor.org/ ScientificPresentationsDatabase/Presentation/65391 [Accessed 14Sep2017].

18. Serag HB, Marrero JA, Rudolph L, Reddy KR. Diagnosis and treatment of hepatocellular carcinoma. Gastroenterology 2008; 134(6):1752-1763.

19. Garcia-CR, Rivera F, Maurel J, Ayoub JP, Moore MJ, Cervantes A. An open-label phase II trial evaluating the safety and efficacy of ramucirumab combined with mFOLFOX-6 as first-line therapy for metastatic colorectal cancer. Oncologist 2014;19(4):350-351.

20. Yoon HH, Bendell JC, Braiteh FS, Firdaus I, Philip PA, Cohn AL. Ramucirumab combined with FOLFOX as front-line therapy for advanced esophageal, gastroesophageal junction, or gastric adenocarcinoma: a randomized, double-blind, multicenter phase II trial. Ann Oncol 2016; 27(12):2196-2203.

21. Qin S, Bai Y, Lim HY, Thongprasert S, Chao Y, Fan J. Randomized, multicenter, open-label trial of oxaliplatin plus fluorouracil/leucovorin versus doxorubicin as palliative chemotherapy in patients with advanced hepatocellular carcinoma from Asia. J Clin Oncol 2013 ;31(28):3501-3508.

22. Park JO. Second-line ramucirumab therapy for advanced hepatocellular carcinoma (REACH): an East Asian and non-East Asian subgroup analysis. Oncotarget 2016 ;7(46):75482-75491. 